TITLE:

\title{
CO2 efflux from leaf litter focused on spatial and temporal heterogeneity of moisture
}

$\operatorname{AUTHOR}(S):$

Ataka, Mioko; Kominami, Yuji; Jomura, Mayuko; Yoshimura, Kenichi; Uematsu, Chiyomi

\section{CITATION:}

Ataka, Mioko ...[et al]. CO2 efflux from leaf litter focused on spatial and temporal heterogeneity of moisture. Journal of Forest Research 2013, 19(2): 295-300

\section{ISSUE DATE:}

2013-10-26

URL:

http://hdl.handle.net/2433/198277

\section{RIGHT:}

The final publication is available at Springer via http://dx.doi.org/10.1007/s10310-0130422-1; この論文は出版社版でありません。引用の際には出版社版をご確認ご利用くだ さい。; This is not the published version. Please cite only the published version. 
$1 \mathrm{CO}_{2}$ efflux from leaf litter focused on spatial and temporal heterogeneity of moisture

2

3 Mioko Ataka a, Yuji Kominami ${ }^{\text {b }}$, Mayuko Jomura ${ }^{c}$, Kenichi Yoshimura ${ }^{\text {b }}$, Chiyomi

$4 \quad$ Uematsu $^{\mathrm{d}}$

5

6 a Laboratory of Forest Hydrology, Division of Environmental Science and Technology,

$7 \quad$ Graduate School of Agriculture, Kyoto University, Kyoto 606-8502, Japan

8 b Kansai Research Center, Forestry and Forest Products Research Institute, Kyoto

9 612-0855, Japan

10 c College of Bioresource Sciences, Nihon University, Fujisawa, Kanagawa 252-0880,

11 Japan

12 d Botanical Gardens, Graduate School of Science, Osaka City University, Osaka

13 576-0004, Japan

14

Corresponding author: Mioko Ataka

16 Corresponding address: Laboratory of Forest Hydrology, Division of Environmental

17 Science and Technology, Graduate School of Agriculture, Kyoto University, Kyoto

18 606-8502, Japan

19 Tel: $+81-75-753-6089$

20 Fax: $+81-75-753-6088$

21 E-mail: mataka@kais.kyoto-u.ac.jp

22

23 Article type: Short communications

24 Subject area and field: Environmental science; Forest soil science

25

26 Page count for the text: 18

27 Number of Figures: 4 


\section{Abstract}

2 Leaf litter respiration $\left(R_{L L}\right)$ was directly measured in situ to evaluate relationships

3 with the water content in leaf litter $(W C)$, which is distributed heterogeneously under

4 natural conditions. To do so, we developed a small, closed static chamber system using

5 an infrared gas analyzer, which can measure instantaneous $R_{L L}$. This study focuses on

6 the measurement of $\mathrm{CO}_{2}$ effluxes from leaf litter using the chamber system in the field

7 and examines the relationship between $R_{L L}$ and $W C$ among seven broadleaf species in a

8 temperate forest. The measurements focused on the position of leaves within the litter

9 layer, finding that both $R_{L L}$ and $W C$ were significantly higher in the lower layer. The

10 value of $R_{L L}$ increased with increasing $W C$, and the response of $R_{L L}$ to $W C$ was similar

11 among all seven species. Moreover, the temporal variation in $W C$ differed among three

12 species and was associated with leaf litter thickness. The observed heterogeneity in $W C$

13 induced by the physical environment (e.g., position and thickness of leaf litter) affects

14 the variation in $W C$ and therefore both $R_{L L}$ and the decomposition rates of organic

15 matter in the litter layer.

17 Keywords Leaf litter respiration $\cdot$ Litter decomposition $\cdot$ Moisture $\cdot$ Spatial and 18 temporal variation $\cdot$ Soil respiration 
1

2

3

4

5

6

7

8

\section{Introduction}

The litter layer (L layer) usually includes most of the labile carbon and most of the microbial biomass held in forest soil (Snajdr et al. 2008). The $\mathrm{CO}_{2}$ efflux from the $\mathrm{L}$ layer is one of the main sources of heterotrophic respiration and soil respiration. Hosoe et al. (2005) reported that the contribution to soil respiration of the $\mathrm{CO}_{2}$ efflux from the

L layer could reach approximately $27 \%$ in a larch forest in central Japan. And, the $\mathrm{CO}_{2}$ efflux from the L layer is strongly controlled by moisture conditions. For example, Cisneros-Dozal et al. (2007) reported that the contribution to soil respiration of the $\mathrm{CO}_{2}$ efflux rate from the L layer varied between 5 and $37 \%$ in response to water additions in a temperate deciduous forest in the United States. The $\mathrm{CO}_{2}$ efflux from the L layer varies over short periods of time (a few minutes to days), followed by rapid changes in the environmental conditions of the litter itself (e.g., litter water content, temperature) (Borken et al. 2003; Cisneros-Dozal et al. 2007). In particular, the frequency of the wetting and drying of litter may affect the total $\mathrm{CO}_{2}$ efflux rate from the $\mathrm{L}$ layer on the forest floor.

The moisture status of the L layer experiences more dynamic wetting and drying processes than the lower soil layer, associated with precipitation and evaporation (Hanson et al. 2003; Jomura et al. 2012). Simard and Main (1982) showed that leaf litter off the ground (the upper layer) is directly exposed to wind and therefore dries more quickly than leaf litter on the ground (the lower layer). The moisture status strongly affects microbial activity, resulting in variation of heterotrophic respiration (Bunnell et al. 1977; DeForest et al. 2009). Therefore, the vertical distribution of leaf litter moisture status inside the L layer would affect the decomposition rate. To examine the characteristics of $\mathrm{CO}_{2}$ efflux from the $\mathrm{L}$ layer, detailed and in situ 
1 measurements of the distribution of moisture status and leaf litter respiration inside

2 the L layer are required.

3

In this study, we developed an easy-to-use chamber system which allow us to

4 measure instantaneous $\mathrm{CO}_{2}$ efflux rates from small leaf litter sample in the field

5 immediately following sampling. We measured leaf litter respiration $\left(R_{L L}\right)$ and leaf

6 litter water content ( $W C$ ) focusing on the vertical position of leaf litter within the $\mathrm{L}$

7 layer, and examined the relationship between $R_{L L}$ and $W C$ within the L layer among

8 seven temperate broadleaf species. We also examined the temporal variations in $W C$

9 and $R_{L L}$ among three species based on litter thickness. From these data, we inferred

10 how physical environments (position and thickness of leaf litter) influence the

11 variations in $W C$ and $R_{L L}$

12 


\section{Materials and Methods}

21 Site description

3

4

This study was conducted in two adjacent temperate forests located in the Botanical Gardens, Faculty of Science, Osaka City University, Japan (34 $766^{\prime} \mathrm{N}, 135^{\circ} 70^{\prime}$ E) at 40-120 m elevation above sea level. Forestation was carried out in the garden for monitoring biomass changes in the 1960s. The sites selected consisted of one deciduous (1.0 ha) and one evergreen broadleaf forest $(1.5 \mathrm{ha})$. The dominant species in the deciduous forest was Quercus serrata $\left(Q_{s}\right)$, and the evergreen forest was composed of a mixture of Castanopsis sieboldii (Cs), Lithocarpus edulis (Le), Machilus thunbergii (Mt), Quercus myrsinaefolia (Qm), Quercus glauca (Qg), and Ilex integra (II).

Annual mean temperature and precipitation from 1981 to 2010 were $15.6^{\circ} \mathrm{C}$ and $1,324 \mathrm{~mm}$, respectively, which were observed at the nearest weather station (AMeDAS, Japan Meteorological Agency, Hirakata), $5.2 \mathrm{~km}$ away from the botanical garden. In the study area, June and July are the rainy season, while August is the driest month. August also had the highest temperature over the study period. Monthly mean temperatures in August 2009 and 2010 were $27.4^{\circ} \mathrm{C}$ and $30.1^{\circ} \mathrm{C}$, respectively.

2 Measurement system of $R_{L L}$

$R_{L L}$ was measured using a static closed-chamber system. The system consisted of an infrared gas analyzer (IRGA, GMP343; Vaisala Group, Vanta, Finland) attached to a small cylindrical chamber, was powered by a portable battery $(14.8 \mathrm{~V})$, and was suitable for measuring the respiration rate of small leaf litter samples. Chambers of three different volumes $(0.308 \mathrm{~L}, 0.375 \mathrm{~L}$, and $0.541 \mathrm{~L})$ were selected according to the available sample sizes. The interior temperature of the chamber was measured with a 
copper-constantan thermocouple.

The $\mathrm{CO}_{2}$ concentration and temperature inside the chamber were recorded at 1-s intervals using a data logger (GL200A; Graphtec, Kanagawa, Japan). The measurement period for each sample was approximately $10 \mathrm{~min} . R_{L L}$ was calculated from the measured increase in $\mathrm{CO}_{2}$ concentration using a linear regression of the linear portion of the resulting data. The IRGA response to a change in $\mathrm{CO}_{2}$ concentration had a time lag of several tens of seconds due to the permeability of the air filter attached to the sensor and increased rate of $\mathrm{CO}_{2}$ concentration per unit time was unstable within one minute after that. Therefore, data from the first 3 min were discarded to maintain high quality data collection. The respiration data for the middle 5-min period were used to calculate leaf litter respiration by the following equation:

$$
R_{L L}=\Delta C_{C O 2} \times \frac{V}{V_{\text {air }}} \frac{273.2}{273.2+T} \frac{M_{\mathrm{CO} 2}}{D W} \times 60^{2},
$$

where $R_{L L}\left(\mathrm{mgCO}_{2} \mathrm{~kg}^{-1} \mathrm{~h}^{-1}\right)$ is $\mathrm{CO}_{2}$ efflux from the leaf litter; $\triangle C C O 2$ is the increased rate of $\mathrm{CO}_{2}$ concentration per unit time $\left(\mathrm{CO}_{2} \mathrm{ppm} \mathrm{s}^{-1}\right) ; V(\mathrm{~L})$ is the volume of the system; $V_{\text {air }}$ is the standard gas volume $\left(22.41 \mathrm{~L} \mathrm{~mol}^{-1}\right) ; T$ is temperature inside the chamber $\left({ }^{\circ} \mathrm{C}\right)$; $M_{C O 2}$ is the molecular weight of $\mathrm{CO}_{2}(44.01 \mathrm{~g})$; and $D W$ is the dry mass of the leaf litter sample (g). When $R_{L L}$ was very small, the resolution of the IRGA (2-3 ppm) was insufficient to measure a clear increase in the $\mathrm{CO}_{2}$ concentration. Thus, when the IRGA measurements indicated increases in the $\mathrm{CO}_{2}$ concentration of less than $3 \mathrm{ppm}$ in the measurement period (5 minutes), $R_{L L}$ was assumed to be $0 \mathrm{mgCO}_{2} \mathrm{~kg}^{-1} \mathrm{~h}^{-1}$.

\section{$3 R_{L L}$ measurements}

(a) Vertical spatial variation in $R_{L L}$ inside the $L$ layer

To evaluate the relationship between $R_{L L}$ and $W C$ among species, we 
1 measured the $R_{L L}$ and $W C$ of the seven litter species from August 4 to 6, 2009.

2 Measurement time was set during the daytime period (12:00 to $16: 00)$ to minimize

3 changes in temperature. The mean temperature in the chamber was $30.1^{\circ} \mathrm{C}$. Changes

4 in temperature during the measurement period were within $\pm 1.5^{\circ} \mathrm{C}$. Leaf litter

5 samples of $Q_{s}$ were collected from the deciduous forest floor, and these of $C_{S}, L e, M t$,

$6 Q m, Q g$, and $I i$ were collected from the evergreen forest floor (Fig. 1a). The ground at

7 the evergreen forest was relatively flat and the thickness of the L layer was approximately $3 \mathrm{~cm}$. In contrast, the terrain of the deciduous forest was complex with steep slopes, which induced heterogeneous thickness in the L layer and litter accumulations in a valley. Therefore, we collected leaf litter from the L layer to approximately $3 \mathrm{~cm}$ in the valley. To evaluate the effect of vertical position in the $\mathrm{L}$ layer on $R_{L L}$ and $W C$, we divided the L layer into three layers (top, middle, and bottom) and obtained three leaves from each layer. We equally divided the L layer into three layers. Thus, thickness of one layer was about $1 \mathrm{~cm}$. Care was taken to ensure that the selected leaves were retaining original form; no obvious symptoms of physical disintegration. After sampling, the $\mathrm{CO}_{2}$ efflux from the sample (three leaves) was measured immediately using the chamber system in the field. The total numbers of measurements made in each layer were 5 and 7 , for $Q_{S}$ and the others, respectively.

\section{(b) Temporal variation in $R_{L L}$}

Leaf litter samples of 3 species $(C e, L e$, and $M t$ ) were collected from the evergreen forest floor in November 2009. To obtain mean $W C$ and $R_{L L}$ in the L layer, 10 dead leaves were formed into one leaf litter stack (Fig. 1b). We prepared two leaf litter stacks each species. Total six leaf litter stacks were fixed to forest floor using wire pins 
1 (diameter $2 \mathrm{~mm}$ ) in November 2009. To examine the temporal changes in $R_{L L}$ according

2 to changes of $W C$ among 3 species, at nine months after setting of leaf litter stacks, we

3 measured $W C$ and $R_{L L}$ on 4 and 7 days (16 and 19 in August 2010) after rainfall (41.0

$4 \mathrm{~mm} \mathrm{day}^{-1}$ ), respectively. The $W C$ and $R_{L L}$ were measured from one leaf separated from

5 a set of 10 dead leaves composing leaf litter stack. The $W C$ and $R_{L L}$ were averaged from

610 dead leaves composing one leaf litter stack. The mean temperature in the chamber

7 was $32.3^{\circ} \mathrm{C}$. Changes in temperature during the measurement were within $\pm 1.5^{\circ} \mathrm{C}$.

8

94 Sample treatment after $R_{L L}$ measurements

After each $R_{L L}$ measurement, litter samples were immediately enclosed in plastic bags. The fresh weight of leaf litter was measured in the laboratory within $24 \mathrm{~h}$ after sampling. Leaf litter samples were oven dried at $60^{\circ} \mathrm{C}$ for $48 \mathrm{~h}$, and $W C$ was calculated using

$$
W C=\frac{(F W-D W)}{D W},
$$

where $F W$ is the fresh mass of the leaf litter sample $(\mathrm{g})$, and $D W$ is the dry mass of the leaf litter sample (g). The area of leaf litter was measured with a LI-COR LI-3000A leaf area meter (Lincoln, NE, USA). Total $\mathrm{C}$ and $\mathrm{N}$ contents were measured using the combustion method in an NC-analyzer (NC-900, Sumitomo Chemical Co., Osaka Japan). Nutrients were determined from five samples randomly selected at each layer in each species. 


\section{$1 \quad$ Results}

Values of $W C, R_{L L}$, and the C:N ratio inside the L layer clearly differed in association with their vertical position in the leaf litter (Fig. 2). Both $W C$ and $R_{L L}$ were significantly higher in the lower layers (Tukey's HSD, $p<0.05$ ). Across all seven species, the $\mathrm{C} / \mathrm{N}$ ratios of the bottom layer were lower than those of the top layer. The differences between the bottom and top layer of each species were significant (Tukey's HSD, $p<0.05)$ except for $Q_{S}$. There was no significant difference in the variations in $R_{L L}$ and $W C$ between species, whereas there was a significant difference in the C:N ratio between species (one-way ANOVA, $p<0.001$ ).

Even though the $R_{L L}$ measurements were conducted under constant temperature $\left(30.1 \pm 1.5^{\circ} \mathrm{C}\right), R_{L L}$ had large variations that followed the $W C$ variations (Fig. 3). The ranges in $R_{L L}$ and $W C$ of the seven species ( $Q_{S}, C_{S}, L e, M t, Q m, Q g$, and $\left.I_{1}\right)$ were 40-1568, 0-2356, 19-1398, 0-1493, 38-1813, 0-1245, and 0-1658 $\mathrm{mgCO}_{2} \mathrm{~kg}^{-1} \mathrm{~h}^{-1}$, and $0.19-2.12,0.13-1.86,0.14-1.93,0.04-2.29,0.17-2.66,0.14-2.92$, and $0.14-2.58 \mathrm{~g}$ $\mathrm{g}^{-1}$, respectively. The value of $R_{L L}$ was occasionally near zero below an $W C$ value of $0.3 \mathrm{~g}$ $\mathrm{g}^{-1}$. Across all seven species, $R_{L L}$ was positively correlated with $W C(p<0.001)$, and the relationship did not differ significantly among the seven species (analysis of covariance, $p=0.07)$

The temporal variation in mean $W C$ among the three species was different (Fig. 4) and associated with the specific leaf surface area (Cs: 87.4, Mt: 81.1 and $L e$ : $69.4 \mathrm{~cm}^{2} \mathrm{~g}^{-1}$ ). The mean $W C$ values of $C S, M t$, and $L e 4$ and 7 days after rainfall were $0.22-0.12,0.36-0.21$, and $0.82-0.16 \mathrm{~g} \mathrm{~g}^{-1}$, respectively. Compared with thinner leaf litter (e.g., $C S$ ), thicker leaf litter (e.g., Le) dried more slowly. Following the variation in $W C, R_{L L}$ varied temporally among the three litter species. The mean $R_{L L}$ values of $C_{S}$, 
$1 M t$, and $L e 4$ and 7 days after rainfall were $109-100,253-94$, and $562-81 \mathrm{mgCO}_{2} \mathrm{~kg}^{-1}$

$2 \mathrm{~h}^{-1}$, respectively. At 4 days after rainfall, the mean $R_{L L}$ of the thicker leaf litter (e.g., $\left.L e\right)$

3 was 5.2 times as large as that of the thinner leaf litter (e.g., $C_{S}$ ). These mean $R_{L L}$

$4 \quad$ similarly varied within range of $R_{L L}$ seen on Fig 3 .

5 


\section{Discussion and Conclusion}

(1)

$\mathrm{mgCO}_{2} \mathrm{~kg}^{-1} \mathrm{~h}^{-1}$, with a mean value of $546 \mathrm{mgCO}_{2} \mathrm{~kg}^{-1} \mathrm{~h}^{-1}$ (Fig. 3). Dilly and Munch (1996) reported that the $R_{L L}$ of black alder litter ranged from approximately 100 to 700 $\mathrm{mgCO}_{2} \mathrm{~kg}^{-1} \mathrm{~h}^{-1}$ at $22^{\circ} \mathrm{C}$ when $W C$ was $2.5 \mathrm{~g} \mathrm{~g}^{-1}$, and that it temporally varied during the course of decomposition. Coxson and Parkinson (1987) showed that the $R_{L L}$ of aspen woodland litter ranged from approximately 50 to $550 \mathrm{mgCO}_{2} \mathrm{~kg}^{-1} \mathrm{~h}^{-1}$ at $18^{\circ} \mathrm{C}$ when $W C$ ranged from 0.3 to $2.7 \mathrm{~g} \mathrm{~g}^{-1}$. Their ranges included the average values of this study. However, our maximum $R_{L L}$ was larger than theirs. We expect that their ranges of $R_{L L}$ would be limited due to the laboratory experiments under a specific environment conditions (e.g., $W C$ and temperature). Our maximum $R_{L L}$ of each species (1245-2356 $\left.\mathrm{mgCO}_{2} \mathrm{~kg}^{-1} \mathrm{~h}^{-1}\right)$ means that $1.6-3.1 \%$ of the substrate could be consumed by respiration only in one day, assuming that the carbon ratio in leaf litter is 0.5 . On the other hand, even at high temperature, $R_{L L}$ widely varied and could reach near zero under specific spatial and temporal condition (Figs. 3, 4). Therefore, large spatial and temporal changes in $R_{L L}$ could occur in the L layer, and this $R_{L L}$ variation would have a high potential to influence the spatial and temporal variation in soil respiration and heterotrophic respiration.

The magnitude of $R_{L L}$ was strongly influenced by $W C$ (Figs. 3, 4) and $W C$ varied both spatially and temporally. First, focusing on the cause of $W C$ variation inside the L layer, $W C$ was highly related to the vertical position of leaf litter within the L layer (Fig. 2). The upper layer tended to be drier than the lower layer. As a result, $R_{L L}$ widely varied between the top and bottom layers and followed the distribution of WC. Taylor and Parkinso (1988) indicated that the upper layer of the L layer was drier 
1 under repeated drying and wetting cycles because this layer was exposed on the surface

2 and the lower layer dried more slowly. Such vertical distribution in $W C$ inside the $\mathrm{L}$

3 layer would affect the magnitude of integrated $R_{L L}$ among layers. As a result of 4 differing moisture histories among layers, a gradient of the degree of decomposition 5 presented by the $\mathrm{C}: \mathrm{N}$ ratio would occur within the L layer (Fig. 2).

6

Second, $W C$ variation was related with leaf litter thickness (Fig. 4). The larger the specific surface area of substrate (e.g., the thinner leaf litter), the faster it dried, as is well known in the field of fire science (Fosberg 1971). Such physical characteristics of litter species affect the wetting and drying cycle of $W C$ and exhibit different temporal variations in $R_{L L}$ among litter species. And, our results showed that the response of $R_{L L}$ to $W C$ was similar among litter species (Fig. 3) despite interspecies differences in chemical quality (C:N ratio). From these results, we speculated that the moisture history of a substrate would finally result in difference of the annual $R_{L L}$ and the decomposition rates between plant species. Virzo De Santo et al. (1993) also reported that the higher ability of leaf litter to retain water would result in the higher decomposition rate. The finding of a relationship between decomposition rate and moisture history was difficult due to many technical aspects. To understand the decomposition process in the forest floor, it is important to monitor moisture conditions in the litter itself, while taking into account physical environments as identified above (position and thickness of leaf litter).

Interest is increasing in the short-term factors that control heterotrophic respiration because of the potential for mitigating climate change, including precipitation and temperature. After rainfall, $R_{L L}$ decreases with drying leaf litter, and the $R_{L L}$ of all species reached near zero below $W C$ of $0.3 \mathrm{~g} \mathrm{~g}^{-1}$. As a result, instantaneous 
$1 R_{L L}$ showed a wide distribution even at the same temperature condition. Direct $R_{L L}$

2 measurement, a measure of microbial activity, can indicate dynamic changes in

3 decomposition processes responding to variations in environmental factors. Our data

4 suggest that history of such environmental condition result in interspecies differences

5 of the decomposition rate. On the other hand, many mass loss studies reported that

6 differences in litter quality between plant species influence the decomposition rate

$7 \quad$ (Hobbie et al. 2006; Salinas 2011). Microbes are directly responsible for majority of

8 litter decomposition and their biomass and community structure could be influenced by

9 the quality of individual plant species (Bardgett and Walker 2004; Ayres et al. 2006). To

10 integrate the effects of environmental conditions and litter quality on decomposition

11 processes, cross-measurement and validation of $R_{L L}$ and microbial composition are

12 required.

13 


\section{Acknowledgments}

2

This research was financially supported by the Nippon Life Insurance

3 Foundation. The authors thank Ms. Iizuka Yumi of the College of Bioresource Science

4 of Nihon University, and Dr. Dannoura Masako, Mr. Sasaki Ryushi, and Ms. Wada

5 Yoshiko of the Laboratory of Forest Utilization of Kyoto University for their assistance

6 with fieldwork and helpful comments on this manuscript.

7 


\section{$1 \quad$ References}

2 Ayres E, Dromph KM, Bardgett RD (2006) Do plant species encourage soil biota that specialise in the rapid decomposition of their litter? Soil Biol Biochem 38:183-186

4

6

Bardgett RD, Walker LR (2004) Impact of coloniser plant species on the development of decomposer microbial communities following deglaciation. Soil Biol Biochem $36: 555-559$

Borken W, Davidson EA, Savage K, Gaudinski J, Trumbore SE (2003) Drying and wetting effects on carbon dioxide release from organic horizons. Soil Sci Soc Am J 67:1888-1896

Bunnell FL, Tait DEN, Flanagan PW, Clever KV (1977) Microbial respiration and substrate weight loss-I: A general model of the influences of abiotic variables. Soil Biol Biochem 9:33-40

Cisneros-Dozal LM, Trumbore SE, Hanson PJ (2007) Effect of moisture on leaf litter decomposition and its contribution to soil respiration in a temperate forest. $\mathrm{J}$ Geophys Res 112:G01013 148-227

Coxson DS, Parkinson D (1987) Winter respiratory activity in aspen woodland forest floor litter and soils. Soil Biol Biochem 19:49-49

DeForest JL, Chen J, McNulty SG (2009) Leaf litter is an important mediator of soil respiration in an oak-dominated forest. Int J Biometeorol 53:1432-1254

Dilly O, Munch JC (1996) Microbial biomass content, basal respiration and enzyme activities during the course of decomposition of leaf litter in a black alder (Alnus glutinosa (L.) Gaertn.) forest. Soil Biol Biochem 28:1073-1081

Fosberg MA (1971) Climatological influences on moisture characteristics of dead fuel: Theoretical analysis. Forest Sci 17:64-72 
1 Hanson PJ, O'Neill EG, Chambers MLS, Riggs JS, Joslin JD, Wolfe MH (2003) Soil

2 respiration and litter decomposition. In: Hanson PJ, Wullschleger SD (eds) North

3 America Temperate Deciduous Forest Responses to Changing Precipitation Regimes.

$4 \quad$ Springer, New York, pp 163-189

5 Hobbie SE, Reich PB, Oleksyn J, Ogdahl M, Zytkowiak R, Hale C, Karolewski P (2006)

6 Tree species effects on decomposition and forest floor dynamics in a common garden.

$7 \quad$ Ecology 87:2288-2297

8 Hosoe F, Moriizumi J, Yamazaki H, Iida T (2005) Evaluation of contribution of soil organic matter to soil respiration from a forest floor: consideration of litter layer (in Japanese with English summary). Summaries of Researches using AMS at Nagoya University 16:127-135

Jomura M, Kominami Y, Ataka M (2012) Differences between coarse woody debris and leaf litter in the response of heterotrophic respiration to rainfall events. J For Res $17: 305-311$

Salinas N, Malhi Y, Meir P, Silman M, Roman-Cuesta R, Huaman J, Salinas D, Huaman V, Gibaja A, Mamani M, Farfan F (2011) The sensitivity of tropical leaf litter decomposition to temperature: results from a large-scale leaf translocation experiment along an elevation gradient in Peruvian forests. New Phytol $189: 967-977$ Spatial variability of enzyme activities and microbial biomass in the upper layers of Quercus petraea forest soil. Soil Biol Biochem 40:2068-2075 
1 Taylor BR, Parkinso D (1988) Does repeated wetting and drying accelerate decay of leaf

$2 \quad$ litter? Soil Biol Biochem 20:647-656

3 Virzo De Santo A, Berg B, Rutigliano FA, Alfani A, Floretto A (1993) Factors regulating

4 early-stage decomposition of needle litters in five different coniferous forests. Soil

$5 \quad$ Biol Biochem 25:1423-1433 
2

3 Fig. 1 Illustration of $R_{L L}$ measurements. Measurements of $R_{L L}$ were conducted by sampling leaf litter from (a) seven species and (b) three species. (a) The L layer was categorized into three layers, and $R_{L L}$ was measured from three leaves in each layer. (b) A set of 10 dead leaves formed into vertical stacks was fixed to forest floor using wire pin, and $R_{L L}$ was measured from a single leaf litter separated from the leaf litter stacks.

9 Fig. 2 Vertical spatial variation in the mean $R_{L L}, W C$, and C:N ratio inside the L layer 10 (top, middle, and bottom layers) among the seven species. Bars indicate standard error.

11 Different letters on the bar indicate significant differences among three layers (Tukey's 12 HSD, $p<0.05)$.

14 Fig. 3 Relationships between $R_{L L}$ and $W C$ of the seven species.

Fig. 4 Temporal variation in mean $R_{L L}$ and $W C$ among three species, 4 to 7 days following rainfall (41.0 mm day ${ }^{-1}$ ), measured in August 2010. Mean $R_{L L}$ and $W C$ were calculated from 10 dead leaves composing one leaf litter stack (Fig. 1b). Bars indicate standard error. Closed circles indicate the relationships between $R_{L L}$ and $W C$ as seen in Fig. 3. 


\section{Ataka Figure 1}
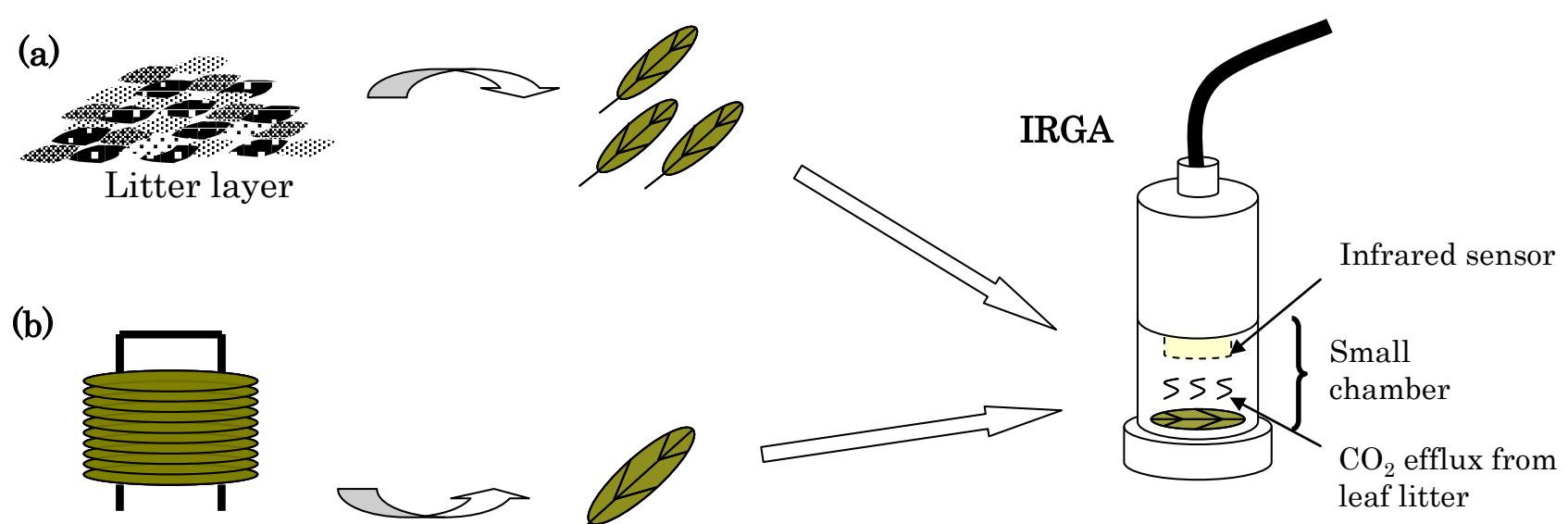

Leaf litter stack

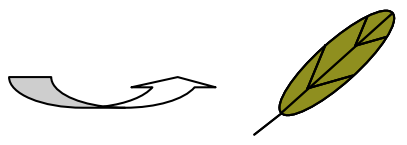
leaf litter 


\section{Ataka Figure 2}

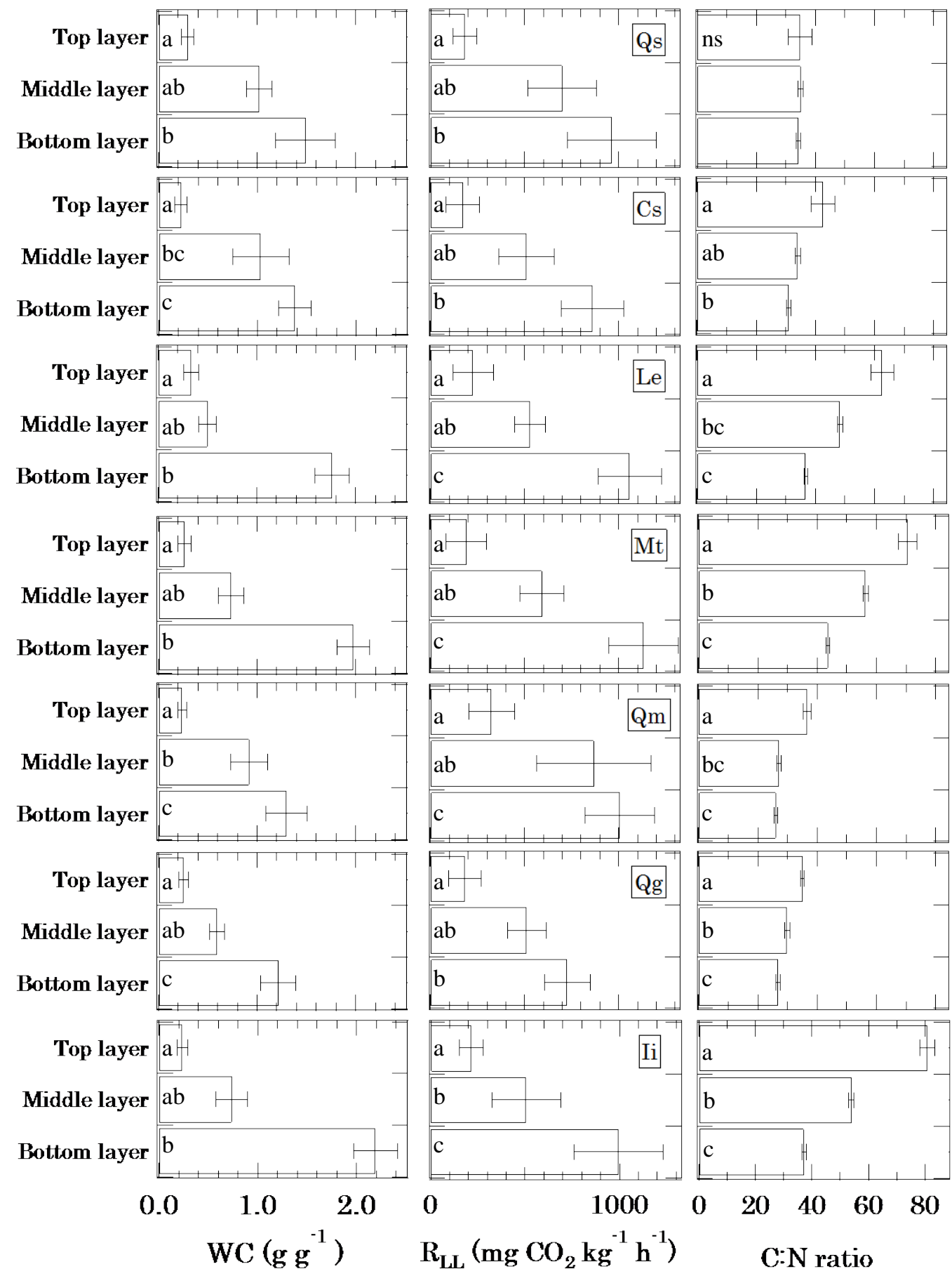




\section{Ataka Figure 3}

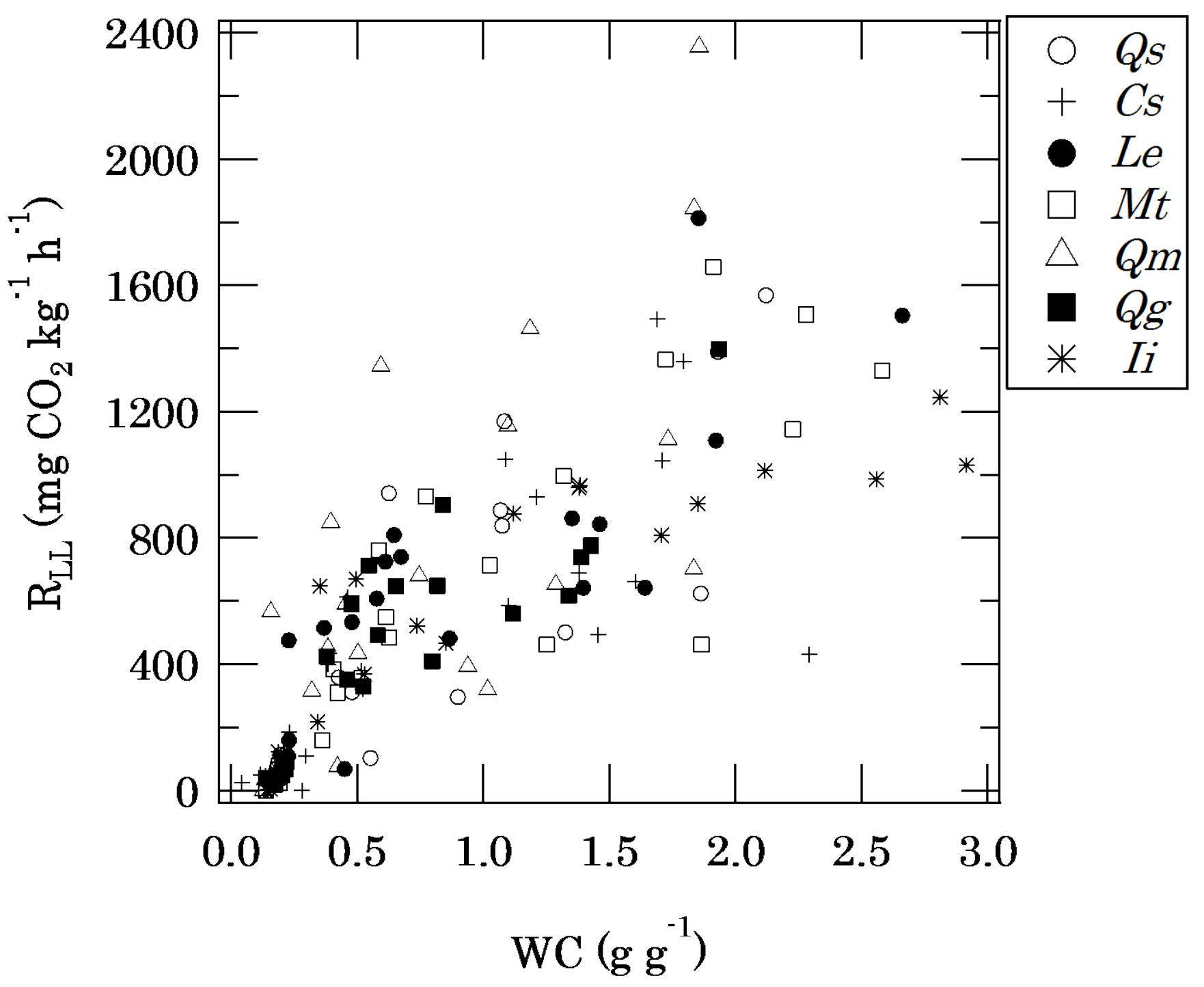




\section{Ataka Figure 4}

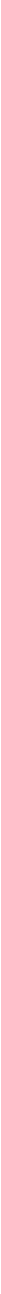

